\title{
Penerapan Restoratife Justice Sebagai Alternatif Penyelesaian Tindak Pidana Penganiayaan Di Satreskrim Polsek Lasem
}

\author{
Arif Septria Hendra Saputra ${ }^{*}$, Gunarto ${ }^{* *}$, Lathifah Hanim ${ }^{* * *}$
}
* Anggota unit Reskrim Polsek Lasem, Mahasiswa Program Magister (S2) Ilmu Hukum Fakultas Hukum UNISSULA Semarang, email : saputraarif877@gmail.com
** Guru Besar Fakultas Hukum UNISSULA Semarang
${ }^{* * *}$ Dosen Fakultas Hukum UNISSULA Semarang

\begin{abstract}
ABSTRAK
Penelitian ini bertujuan untuk mengetahui dasar hukum pelaksanaan medisai penal terhadap kasus penganiayaan di Polsek Lasem, dan untuk mengetahui cara pelaksanaan mediasi penal yang dilakukan di Polsek Lasem untuk memperoleh kesepakatan damai antara korban penganiayaan dan pelaku penganiayaan. Metode penelitian menggunakan jenis penelitian kualitatif dengan pendekatan yuridissosiologis. Hasil penelitian yaitu bahwa dasar hukum pelaksanaan mediasi penal di Polsek Lasem pada saat ini belum ada dasar hukumnya secara integral yang mengatur jenis tindak pidana apa yang bisa diselesaikan secara mediasi penal di Kepolisian. Cara pelaksanaan mediasi penal yang dilakukan di Polsek Lasem untuk memperoleh kesepakatan damai antara korban penganiayaan dan pelaku penganiayaan adalah dilakukan disebuah ruangan khusus di Polsek Lasem agar para pihak bernegoisasi untuk memperoleh kesepakatan damai dengan seorang mediator dari penyidik- penyidik Polsek Lasem. Model mediasi penal yang dipakai oleh Polsek Lasem adalah model mediasi penal Victim Offenders Mediation dan Family and Community Group Conferences. Simpulan penelitian ini adalah acuan pelaksanaan mediasi penal merujuk pada groun norm yaitu Pancasila Sila ke-5, UUD 1945 dan pasal -pasal secara parsial yang tercantum di dalam KUHAP, dan Undang -Undang No.2 Tahun 2002 Tentang Kepolisian Negara Republik Indonesia. Pelaksanaan mediasi penal dalam penyelesaian tindak pidana di Polsek Lase. menggunakan model mediasi penal Victim-Offenders Mediationdan penal Family and Community Group Conferences

Kata Kunci : Restorative Justice, Tindak Pidana penganiayaan
\end{abstract}

\section{ABSTRACT}

This study aims to determine the legal basis for the implementation of penal mediation against cases of abuse in Lasem Police, and to know how the implementation of penal mediation conducted in Lasem Police to obtain a peace agreement between the victims of persecution and perpetrators of the persecution. The research method uses qualitative research the socio-juridical approach. The results of the study that the legal basis for the implementation of penal mediation in Lasem Police there is currently no act what kind of criminal act can be resolved in mediation penal. The way the implementation of penal mediation conducted in Lasem Police to obtain a peace agreement between the victim and the perpetrator of persecution are persecution conducted a special room in the Lasem Police that the parties negotiate to obtain peace agreement with a mediator from the Police investigator. Penal mediation model used to Lasem Police Station is a model penal mediation VictimOffenders Mediation and Family and Community Group Conferences. Conclusions This study is the reference implementation of penal mediation refers to the ground norm namely Pancasila Sila ke-5, UUD 1945 and Article-Article partially listed the KUHAP and statute No. 2 of 2002 on the Police of the 
Republic of Indonesia. Implementation of penal mediation in the settlement of a criminal offense in Lasem Police penal mediation model Victim -Offenders Mediation and Family and Community Group. Keywords: Restorative Justice, Crime of Persecution

\section{PENDAHULUAN}

Penyelesaian pada konflik -konflik yang terjadi di dalam masyarakat dapat dilakukan dengan dua pilihan, yaitu dengan jalur litigasi dan non-litigasi. Jalur litigasi merupakan cara penyelesaian masalah melalui jalur Pengadilan, sedangkan non-litigasi merupakan cara penyelesaian masalah di luar Pengadilan. Dalam perspektif hukum pidana di Indonesia ini sudah mengenal penyelesaian perkara pidana di luar pengadilan, atau sering disebut dengan Alternative Dispute Resolution. Hal ini diupayakan untuk keadilan Restorative dengan menyeimbangkan perbuatan pelaku tindak pidana dengan akibat yang ditimbulkan. Mediasi Penal merupakan salah satu bentuk penyelesaian sengketa di luar Pengadilan (Alternative Dispute Resolution) yang lebih populer di lingkungan kasus-kasus perdata, namun bukan berarti tidak dapat diterapkan di lingkungan hukum pidana (http://bardanawawi.wordpress.com/2009/12/27/ mediasi-penal-di-luar-pengadilan).

Mediasi Penal merupakan terobosan hukum yang diterapkan oleh aparat penegak hukum dengan mengacu pada proses pendekatan Restorative Justice, mengingat terdapat tujuan untuk mendamaikan korban tindak pidana dengan pelaku tindak pidana melalui mediasi guna menyelesaikan perkara, mengembalikan serta memperbaiki kerusakan dan kerugian yang ditimbulkan akibat suatu perkara pidana. Cara demikian dapat mempertemukan keluarga kedua belah pihak yaitu keluarga korban dan pelaku, atau dengan melibatkan tokoh masyarakat untuk menemukan solusi yang terbaik. Dalam penerapan praktik mediasi penal di Kota Lasem, kiranya dapat menyelaraskan dengan tradisi kebudayaan adat masyarakat Kota Lasem yang masih kental khususnya di Wilayah Kecamatan Lasem. Hal demikian dikarenakan banyak masyarakat pendatang dari luar Kota Lasem yang tinggal sementara di wilayah Kecamatan Lasem sehingga rentan terjadi pertikaian yang menyebabkan timbulnya kejahatan seperti penganiayaan dan penganiayaan ringan. Dalam konteks ini aparat penegak hukum Polsek Lasem seringkali turuntangan dalam menyelesaikan kasus seperti kasus penganiayaan ringan. Cara penyelesaian oleh Polsek Lasem terkadang ada yang diproses lanjut dan ada juga yang diselesaikan secara mediasi penal. Dalam penyelesaian tersebut sebenarnya Polsek Lasem merupakan wadah yang mefasilitasi berjalannya mediasi penal. Dari mediasi penal tersebut diharapkan dapat menghasilkan Win-Win Solution bagi korban dan pelaku tindak pidana penganiayaan.

Dari uraian latar belakang tersebut maka diangkatlah topik judul tesis tentang "Penerapan Restoratife Justice Sebagai Alternatif Penyelesaian Tindak Pidana Penganiayaan Di Satreskrim Polsek Lasem". Berdasarkan uraian kasus diatas maka akan dideskripsikan dan dianalisa mengenai dasar hukum pelaksanaan mediasi penal terhadap kasus penganiayaan di Polsek Lasem dan cara pelaksanaan mediasi penal yang dilakukan di Polsek Lasem untuk memperoleh kesepakatan damai antara korban penganiayaan dan pelaku penganiayaan.

\section{Metode Penelitian}

Penelitian ini adalah penelitian hukum menggunakan jenis penelitian kualitatif dengan pendekatan Yuridis Sosiologis (sosio-legal approach). Pendekatan Yuridis Sosiologis adalah penelitian hukum dipelajari dan diteliti sebagai studi law in action karena mempelajari dan meneliti Cacuk Sudarsono/ Unnes Law Journal 4(1) (2015)22hubungan timbal balik antara hukum dan lembagalembaga sosial yang lain studi hukum law in action merupakan studi sosial non doktrinal dan bersifat 
empiris (Ronny, 1988: 34). Sumber data menggunakan data primer, berupa wawancara dan sumber data sekunder, berupa Pancasila, UUD 1945, Undang -Undang nomor 8 Tahun 1981 tentang KUHAP, Undang -Undang Nomor 2 Tahun 2002 Tentang Kepolisian Negara Republik Indonesia. Surat Kapolri No. B/3022/XXI/2009/SDEOPS yang menjelaskan bahwa perkara yang telah diselesaikan melalui Alternative Dispute Resolutionagar tidak dilakukan proses hukum berikutnya. Teknik pengumpulan data menggunakan teknik wawancara, dokumentasi, dan studi pustaka. Analisis Data menggunakana Hipotesis Kerja. Analisa data adalah proses mengorganisasikan dan mengurutkan data ke dalam pola, kategori, dan satuan uraian dasar sehingga dapat ditemukan tema dan ditemukan hipotesis kerja seperti yang disarankan oleh data (Moleong, 2004:247).

\section{HASIL PENELITIAN DAN PEMBAHASAN}

Dasar hukum pelaksanaan mediasi penal terhadap kasus penganiayaan di Polsek Lasem berdasarkan hasil wawancara yang dilakukan dengan penyidik IPDA SUDIBIYONO., S.H selaku Kanit Reserse dan Kriminal (RESKRIM) Polsek Lasem sebagai informan pada tanggal 10 Januari 2018 Pukul 09:56 WIB terkait dasar hukum dalam pelaksanaan mediasi penal di Polsek Lasem, menyatakan bahwa: "Dasar hukum penerapan mediasi penal di Polsek Lasem belum ada dasar hukumnya. Penyelesaian tindak pidana pengaiyaan secara mediasi penal di Polsek Lasem berdasarkan kesepakatan kedua belah pihak antara korban tindak pidana penganiayaan dan pelaku tindak pidana penganiayaan."

Mediasi penal merupakan proses penyelesaian perkara pidana di luar pengadilan yang dalam praktiknya bisa diterapakan ditahap Kepolisian, Kejaksaan, dan Pengadilan. Martin Wright (dikutip dari Suseno dan Nella Sumika Putri, 2018 : 44) adalah suatu proses dimana korban (korban -korban) dan pelaku (pelaku -pelaku) berkomunikasi dengan bantuan pihak ketiga yang tidak memihak, baik secara langsung (bertatap muka) maupun secara tidak langsung melalui pihak ketiga, menyanggupkan atau memungkinkan korban (korban -korban) mengekpresikan kebutuhan -kebutuhan dan perasaan perasaan mereka dan pelaku (pelaku -pelaku) untuk menerima dan bertindak berdasarkan tanggung jawab mereka. Mediasi penal diterapakan dalam menyelesaikan sebuah tindak pidana tertentu yang bisa dikategorikan untuk mengurangi penumpukan perkara pidana di tingkat Pengadilan (judex facti).

Dalam pelaksanaan mediasi penal dalam penyelesaian tindak pidana penganiayaan di Polsek Lasem, belum ada dasar hukum pelaksanaan mediasi penal dalam penyelesaian tindak pidana penganiayaan di Polsek Lasem yang secara integral yang mengatur tentang mediasi penal. Praktik Mediasi penal sering dilakukan dilapangan sebagai upaya terobosan hukum di Kepolisian dengan melihat, menimbang sisi keadilan bagi semua pihak. Keadilan tersebut berdasarkan ground norm(norma dasar) falsafah negara yaitu Pancasila khususnya Sila ke- 5 yang berbunyi "keadilan sosial bagi seluruh rakyat Indonesia."

Meskipun falsafah negara secara spesifik tidak menyatakan adanya ruang bagi mediasi penal, akan tetapi adanya essensi nilai -nilai keadilan dalam mendorong Arif Septria Hendra Saputra Menerapkan Restoratife Justice sebagai alternative penyelesaian tindak pidana penganiayaan yang dapat digunakan sebagai dasar mediasi penal. Selain Pancasila Sila ke-5, keadilan sosial juga diatur di dalam konstitusi negara Republik Indonesia yaitu dalam pembukaan UUD 1945 alinea ke-4, selain dari itu terdapat aturan lain dalam Pasal 30 ayat (4) UUD 1945 yang berbunyi "Kepolisian Negara Republik Indonesia sebagai alat negara yang menjaga keamanan dan ketertiban masyarakat bertugas melindungi, mengayomi, melayani masyarakat, serta menegakkan hukum". 
Melihat penerapan mediasi penal di Polsek Lasem, secara tidak langsung penyidik Polsek Lasem telah menerapkan bunyi pasal tersebut melalui mediasi penal. Hal itu dikarenakan dalam pelaksanaan mediasi penal di Polsek, Penyidik mendasarkan pada kesepakatan kedua belah pihak yang berperkara. Adanya kesepakatan tersebut merupakan wujud perlindungan, pengayoman, pelayanan, dan penegakan hukum yangdisesuaikan dengan kultur masyarakat setempat. Pasal 7 ayat (1) huruf $j$ KUHAP yang berbunyi "Mengadakan tindakan lain menurut hukum yang bertanggung jawab". Dalam pasal ini secara tidak langsung mengatur tentang penyidik untuk melakukan tindakan lain yang sesui dengan keadaan yang dihadapinya. Meskipun demikian tindakan lain yang dilakukan penyidik menerapkan mediasi penal tetap berdasarkan pada kespatakan kedua belah pihak yang berperkara.

Bunyi Pasal 7 ayat (1) huruf j KUHAP juga dipertegas kembali dalam Pasal 16 ayat (1) huruf I Undang -Undang Nomor 2 Tahun 2002 Tentang Kepolisian Negara Republik Indonesia yang berbunyi "Mengadakan tindakan lain menurut hukum yang bertanggung jawab".Selain itu terdapat ketentuan lain dalam Pasal 18 ayat (1) Undang -Undang Nomor 2 Tahun 2002 Tentang Kepolisian Negara Republik Indonesia yang berbunyi "Untuk kepentinganumum pejabat Kepolisian Negara Republik Indonesia dalam melaksanakan tugas dan wewenangnya dapat bertindak lain menurut penilaiannya sendiri". Pasal ini sebenarnya juga dapat dijadikan acuan dalam penerapan mediasi penal, meskipun tidak secara spesifik mengatur mengenai mediasi penal di Kepolisian. Setidaknya bunyi pasal tesebut memberi ruang bagi Kepolisian khususnya Polsek Lasem untuk melakukan penerapan restortife Justice untuk kepentingan umum berdasarkan kesepakatan pihak-pihak yang berperkara dan masyarakat. Selain beberapa aturan diatas pelaksanaan mediasi penal pernah mengacu pada Surat Kapolri No Pol : B/3022/XII/2009/SDEOPS, tanggal 14 Desember 2009 tentang Penanganan Kasus Melalui Alternative Dispute Resolusion(ADR) yang berisi sebagai berikut:

1. Mengupayakan penanganan kasus pidana yang mempunyai kerugian materi kecil, penyelesaiannya dapat diarahkan melalui konsep ADR

2. Penyelesaian kasus pidana dengan menggunakan ADR harus disepakati oleh pihak - pihak yang berperkara namun apabila tidak terdapat kesepakatan baru diselesaikan sesuai dengan prosedur hukum yang berlaku secara profesional dan proporsional.

3. Penyelesaian kasus pidana yg menggunakan ADR harus berprinsip pada musyawarah mufakat dan harus diketahui oleh masyarakat sekitar dengan menyertakan RT/ RW setempat.

4. Penyelesaian kasus pidana dengan menggunakan ADR harus menghormati norma hukum sosial atau adat serta memenuhi azas keadilan.

5. Memberdayakan anggota Polmas dan memerankan FKPM yang ada di wilayah - masing -masing untuk mampu mengidentifikasi kasus -kasus pidana yang mempunyai kerugian

\section{PENUTUP}

\section{Simpulan}

Dasar hukum pelaksanaan mediasi penal dalam menyelesaikan tindak pidana penganiayaan di Polsek Lasem sebenarnya belum ada dasar hukum perundang -undangan yang mengatur pelaksanaan mediasi penal di tingkat Kepolisian secara integral, namun dalam praktiknya pelaksanaan mediasi penal ditingkat Kepolisian sering dilakukan khususnya di Polsek Lasem dalam penyelesaian tindak pidana penganiayaan berdasarkan kesepakatan kedua belah pihak yang berperkara dan mengacu pada Pancasila Sila ke-5, pembukaan UUD 1945 Alinea ke-4, Pasal 30 ayat (4) UUD 1945, Pasal 7 ayat (1) huruf j KUHAP, Pasal 16 ayat (1) huruf I UU No. 2 Tahun 2002 Tentang Kepolisian Negara Republik Indonesia, Pasal 18 ayat (1) UU No. 2 Tahun 2002 Tentang Kepolisian Negara Republik Indonesia. 
Model mediasi penal yang dipakai di Polsek Lasem ialah model mediasi penal Victim-Offenders Mediation yaitu model mediasi yang melibatkan kedua belah pihak yang berperkara beserta keluarganya masing-masing untuk bernegoisasi supaya memperoleh kesepakatan damai, dengan menggunakan mediator dari Polisi sebagai penengah dalam perkara itu. Dan model mediasi penal Family and Community Group Conferences yaitu model mediasi yang melibatkan kedua belah pihak yang berperkara beserta keluarganya masing -masing untuk bernegoisasi dan tokoh masyarakat yang dianggap mempunyai peranan penting dalam berjalannya proses negoisasi supaya memperoleh kesepakatan damai, dengan menggunakan mediator dari Polisi sebagai penengah dalam perkara itu.

\section{Saran}

Pemerintah supaya membuat undang -undang tentang mediasi penal yang secara integral mengatur jenis tindak pidana apa saja yang bisa diselesaikan secara mediasi penal ditingkat Kepolisian.Pemerintah supaya membuat undang -undangmengenai tatacara pelaksanaan mediasi penal ditingkat Kepolisian supaya praktik penerapannya dilapangan ada dasar hukumnya yang jelas.Pemerintah agar menyikronkan antara RKUHP dengan RKUHAP yang mengatur pasal terkait penyelesaian perkara pidana di luar Pengadilan.

\section{DAFTAR PUSTAKA}

Buku Arief, Barda Nawawi. 2008. Kebijakan Hukum Pidana Perkembangan Penyusunan Konsep KUHP Baru. Jakarta: Kencana Prenada Media Group.

Ashshofa, Burhan. 2007. Metode Penelitian Hukum. Jakarta: Rineka Cipta.

Chazawi, Adami. 2001. Kejahatan Terhadap Tubuh Dan Nyawa. Jakarta: Raja

Grafindo Persada.

Effendi, Tolib. 2013. Sistem Peradilan Pidana Perbandingan Komponen dan

Proses Sistem Peradilan Pidana Di Beberapa Negara.Yoyakarta: Pustaka Yustisia.

Mahmud Marzuki, Peter. 2007. Penelitian Hukum. Jakarta: Peranada Media Group.

Miles, Matthew B. 1992. "Analisis data kualitatif : buku sumber tentang metode-metode baru

Matthew B. Miles dan A. Michael Huberman ;penerjemah Tjetjep Rohendi Rohidi ".

Moelong, Lexy J.2004. Metode Penelitian Kualitatif. Bandung: Remaja Rosdakarya.

Muhammad, Rusli. 2011. Sistem Peradilan Pidana Indonesia. Yogyakarta: UII Press Yogyakarta.

Suparmin. 2012. Model Polisi Pendamai Dari Perspektif Alternative Dispute Resolution Semarang:Badan Penerbit Diponegoro.

Suseno, Sigit dan Nella Sumika Putri. 2013. Hukum Pidana Indonesia Cacuk Sudarsono/ Unnes Law Journal 4(1) (2015)34Perkembangan dan Pembaharuan.Bandung: Remaja Rosdakarya.

Sumber dari Falsafah Negara, Perundang -Undangan, dan Peraturan -Peraturan lainnya:PancasilaUUD RI 1945Undang -Undang nomor 1 Tahun 1946 tentang Hukum Pidana Undang -Undang nomor 8 Tahun 1981 tentang Hukum Acara Pidana Undang -Undang nomor 2 Tahun 2002 tentang Kepolisian Negara Republik Indonesia

Peraturan Kapolri No. 7 Tahun 2008 tentang Kewenangan Pada Polisi Dalam 
menyelesaikan Masalah Melalui Upaya Damai

Surat Kapolri No. Pol: B/3022/XII/2009/SEDOPS tentang Penanganan Kasus Melalui Alternatif Dispute Resolusion Rancagan Undang -Undang Kitab Hukum pidana Tahun 2012 Rancangan Undang Undang Kitab Hukum Acara Pidana Tahun 2013

Sumber dari Tesis, Skripsi, Jurnal, Artikel, dan Internet:Keyzha Natakharisma, I Nengah Suantra. Mediasi Dalam Penyelesaian Perkara Pidana Di Indonesia.

Jurnal FH Universitas Udayana, 2013.Marlyn Jane Alputila, Syukri Akub, dan Slamet Sampurno Soewondo. Peran Kepolisian Dalam Proses Penyidikan Kasus Kekerasan Dalam Rumah Tangga Di Polres Ambon.

Jurnal FH Universitas Hasanuddin, 2012.Mochamad Bintoro, Kewenangan Polri Melakukan Mediasi Penal Dalam Penyidikan Kejahatan Ringan Di KepolisianResorPemalang.

SkripsiFHUniversitasPancaSaktiTegal,2011.

http://bardanawawi.wordpress.com/2009/12/27/mediasi-penal-di-luar-pengadilan. 